\title{
Field Study to Explore Possible Effects of Styrene on Auditory Function in Exposed Workers
}

\author{
Jörg HOFFMANN ${ }^{1 *}$, Andreas IHRIG ${ }^{1}$, Sebastian HOTH ${ }^{2}$ and Gerhard TRIEBIG ${ }^{1}$ \\ ${ }^{1}$ Institute and Outpatient Clinic for Occupational and Social Medicine, University Hospital Heidelberg, \\ VOßSTRAßE 2, 69115 Heidelberg, Germany \\ ${ }^{2}$ ENT-Department, University Hospital Heidelberg, Germany
}

Received May 9, 2005 and accepted November 25, 2005

\begin{abstract}
Objectives: We conducted this study to examine, whether occupational styrene exposures are associated with reduced hearing ability. Methods: The auditory function was investigated by pure tone audiometry and registration of transitory evoked otoacoustic emissions (TEOAE) in 32 workers of a fibre-reinforced plastic boat building factory. Sixteen subjects were laminators (mean age: $41 \mathrm{yr}$ (SD: 8)) and therefore regularly exposed to styrene with mean duration of exposure to styrene of 7.5 yr (SD 5.0). The tests were applied to a reference group of 16 workers (mean age: $39 \mathrm{yr}$ (SD: 8)) who were not directly exposed to styrene but had a similar noise exposure. Results: A few and isolated correlations between the parameters of hearing acuity and exposure indices, such as current internal styrene exposures (sum of MA and PGA) and duration of styrene exposure, were statistically significant, but no consistent association was found. Conclusion: The results of this study do not support the assumption of an ototoxic effect of chronic styrene exposure in workers.
\end{abstract}

Key words: Ototoxicity, Styrene, Hearing loss, Laminators

Styrene is largely used in the polystyrene-plastic industry. High exposures can occur in reinforced-plastic industry, especially in the production of large items such as boats, which involve manual lay-up and spray-up operations $^{1,2)}$.

In experimental studies an ototoxic effect of high styrene concentrations could be demonstrated in rats ${ }^{3}$. Morphological analysis by light and electron microscopy revealed a severe loss of outer hair cells in the third row, particularly in the upper basal and lower middle regions of the cochlea. The threshold for this effect appears to be between 300 and $600 \mathrm{ppm}^{4)}$. Furthermore there are hints from new studies, that combined exposures to styrene and noise may act synergistically in rats ${ }^{5)}$. The results of studies addressed to the potential effect of styrene exposures on hearing loss in humans at workplaces are equivocal ${ }^{6-12)}$.

The purpose of this study was to examine, whether styrene exposure at typical industrial workplaces is associated with reduced hearing ability in exposed workers or

*To whom correspondence should be addressed. not. In the search for some effect of styrene upon human hearing most of the investigators used hearing threshold levels in pure-tone audiometry to quantify any loss of hearing ability. This traditional approach may not be sufficient or reliable to investigate the effects of styrene exposure on auditory function. Therefore we also measured transient (click) evoked otoacoustic emissions (TEOAE) to study cochlear function with a sensitive, noninvasive and objective manner in addition to conventional pure-tone audiometry.

The study population consisted of 32 male workers of a boat building factory. Out of them, 16 laminators were regularly exposed to styrene vapours. Mean duration time of styrene exposure was $8 \mathrm{yr}$ (standard deviation (SD) 5). With regard to age, reported previous noise exposure and socio-economic status, the 16 subject of the control group were comparable to the exposed workers. Control persons were not directly exposed to styrene or other chemicals. The mean age was 41 (SD 8) yr in the laminator group and 39 (SD 8) yr in the control group.

Data collection consisted of interviews in which each worker was asked about previous affections of the ear, 
Table 1. Results in pure tone audiometry and parameters of TEOAE. Given are the mean values and standard deviations

\begin{tabular}{lccc}
\hline & $\begin{array}{c}\text { Styrene-exposed } \\
\text { workers } \\
(N=16)\end{array}$ & $\begin{array}{c}\text { controls } \\
(N=16)\end{array}$ & $\begin{array}{c}t \text {-Test } \\
(\mathrm{p})\end{array}$ \\
\hline $\begin{array}{l}\text { Pure tone audiometry } \\
\text { (Hearing level in dB(A)) }\end{array}$ & & & \\
Frequency $250 \mathrm{~Hz}$ & $14.0 \pm 3.2$ & $14.3 \pm 3.6$ & 0.72 \\
Frequency $500 \mathrm{~Hz}$ & $13.6 \pm 3.2$ & $14.5 \pm 4.1$ & 0.48 \\
Frequency $1,000 \mathrm{~Hz}$ & $13.3 \pm 3.4$ & $14.7 \pm 5.3$ & 0.33 \\
Frequency $2,000 \mathrm{~Hz}$ & $15.9 \pm 5.4$ & $16.7 \pm 7.8$ & 0.74 \\
Frequency $4,000 \mathrm{~Hz}$ & $27.8 \pm 11.1$ & $30.6 \pm 18.5$ & 0.58 \\
Frequency $8,000 \mathrm{~Hz}$ & $26.5 \pm 11.0$ & $27.6 \pm 15.3$ & 0.79 \\
\hline TEOAE: & & & \\
Amplitude in dB SPL & $7.7 \pm 3.6$ & $9.2 \pm 3.4$ & 0.17 \\
Reproducibility $(\%)$ & $64 \pm 16$ & $65 \pm 24$ & 0.51 \\
\hline
\end{tabular}

personal and family history of hearing deficits and exposure to high levels of noise or intake of ototoxic drugs in the past. An affection of the middle ear was excluded in all persons by otoscopy and tympanometry. Participation was voluntary and informed consent was obtained for all examination procedures.

According to the recommendation of the Commission for the Investigation of Health Hazards of Chemical Compounds in the work area ${ }^{13)}$, the sum of styrene metabolites mandelic acid (MA) and phenylglyoxylic acid (PGA) was used to evaluate the current styrene exposure. Therefore spot urine samples were collected at the end of the shift on Thursday and analyzed by high-pressure-liquid-chromatography under quality control scheme. For details see ${ }^{14)}$.

The mean value of the sum of MA and PGA was 656 mg/g creatinine (SD 639) (median: 446; range: 72-2, 213) for the laminators and $130 \mathrm{mg} / \mathrm{g}$ creatinine (SD 129) (median: 76; range: 25-478) in case of the reference group. The occupational exposure of seven workers exceeded the German exposure limit value [biological tolerance value (BAT)] of $600 \mathrm{mg} \mathrm{MA}+\mathrm{PGA} / \mathrm{g}$ creatinine ${ }^{13}$ ).

As an indicator of chronic styrene exposure we used the duration of employment in a working area with styrene exposure.

We used two methods to examine hearing ability. Firstly hearing thresholds for air conduction were measured for both ears of each subject at the frequencies $0.125,0.25,0.5,1,2,4$ and $8 \mathrm{kHz}$ by means of pure-tone audiometry (Dorn AT 210 audiometer). Secondly the transient evoked otoacoustic emissions (TEOAE) of both ears were registered at the end of the shift. For this purpose we used an ILO 88 Echoport (Otodynamics Ltd., UK) in the non-linear stimulation mode with a click level of $80 \mathrm{~dB}$ SPL p.e., which was adjusted individually. The
TEOAE was extracted from the noisy microphone signal by averaging the responses to 260 stimulus sequences. A low cut filter was applied to avoid influences by background noise level, which was determined between 33 and $60 \mathrm{~dB}$ (A) according to the frequency. For statistical evaluations we calculated the mean value of each parameter from the results of the left and right ear.

The statistical analysis was performed with SPSS 11.5 statistical software. Differences between groups are examined by t-tests. To check associations between variables we applied partial correlation controlling for 'age'. Results of the statistical analysis are considered as significant if $\mathrm{p}<0.05$.

The results in pure tone audiometry and parameters of TEOAE in styrene-exposed workers vs. controls are presented in the Table 1 . There are no significant differences in the mean values of hearing ability. The mean value of the amplitudes of the TEOAE was $7.7 \pm 3.6 \mathrm{~dB}$ SPL (sound pressure level) in the exposed group and $9.9 \pm 3.2 \mathrm{~dB}$ SPL in the reference group with a mean reproducibility of $64 \pm 16 \%$ vs. $72 \pm 24 \%$. These differences were also not statistically significant.

The correlation coefficients between the parameters of hearing acuity and different indices of styrene exposure are listed in the Table 2. Concerning the duration of styrene exposure there is one (out of six) positive significant association with the hearing level, in specific at the frequency of $1 \mathrm{kHz}(\mathrm{p}=0.04)$. Using the internal styrene exposure parameters the correlation at the frequency of $500 \mathrm{~Hz}$ was significant $(\mathrm{p}=0.04)$.

Main finding of this study is, that chronic styrene exposures are not associated with a significant hearing dysfunction. The comparison of the frequency-dependent hearing losses in pure tone audiometry as well as the mean values of TEOAE-parameters showed no differences 
Table 2. Correlation coefficients between hearing levels in pure tone audiometry, parameters of TEOAE and styrene exposure indices in 16 exposed workers

\begin{tabular}{lcc}
\hline & $\begin{array}{l}\text { Duration of styrene } \\
\text { exposure }\end{array}$ & $\begin{array}{l}\text { Sum of MA and } \\
\text { PGA }\end{array}$ \\
\hline $\begin{array}{l}\text { Pure tone audiometry } \\
\text { (Hearing level in dB(A)) }\end{array}$ & & \\
Frequency: $250 \mathrm{~Hz}$ & 0.21 & 0.52 \\
Frequency: $500 \mathrm{~Hz}$ & 0.27 & $0.53^{*}$ \\
Frequency: $1,000 \mathrm{~Hz}$ & $0.53^{*}$ & 0.44 \\
Frequency: $2,000 \mathrm{~Hz}$ & 0.31 & 0.41 \\
Frequency: $4,000 \mathrm{~Hz}$ & 0.06 & 0.44 \\
Frequency: $8,000 \mathrm{~Hz}$ & 0.39 & -0.34 \\
TEOAE & & 0.25 \\
amplitude in dB SPL & 0.14 & -0.01 \\
reproducibility & 0.14 & \\
\hline
\end{tabular}

*=significant $(\mathrm{p}<0.05)$.

between the group, which is exposed directly to styrene and the control group of the same plant.

Within the six correlations between hearing thresholds in pure-tone audiometry as parameters of hearing ability and styrene exposure indices, there was one significance for the hearing level at frequency of $1,000 \mathrm{~Hz}$ and the duration of styrene exposure. Furthermore also one correlation was significant for the current internal exposure (sum of MA and PGA) and the hearing threshold at frequency of $500 \mathrm{~Hz}$. No significant correlations were found for the results of the parameters of TEOAE and styrene exposures. This can be attributed at least partially to the unfavourable conditions for the measurement of the very soft acoustic signals emerging from the inner ear.

In regard to biological plausibility the single significant associations between various frequencies of hearing acuity and styrene exposures encountered in this study do not lead to a convincing evidence for an styrene effect on hearing ability.

A strength of this study is the use of transient evoked otoacoustic emissions (TEOAE) in the assessment of inner ear hearing loss. OAE are acoustic signals, generated by the motility of cochlear outer hair cells (OHC). Because the ototoxic effects induced by styrene primarily affect these cells in rats, the specificity of OAEs for indicating the healthiness of $\mathrm{OHC}$ activity make them well-suited to detect a styrene induced effect on inner ear function objectively ${ }^{5,15)}$. However, the criteria of normal otoacoustic emissions are not yet standardized and different measures of otoacoustic emissions have been used in various settings.

On the other hand, there are some weaknesses in our study, which have to be considered adequately. First of all the impact of our results is limited by the small number of subjects and the fact that the controls had mea- surable concentrations of MA and PGA in urine too. Considering possible acute effects we had to make a clear distinction between exposed persons and controls. Therefore we performed the calculations of table 1 a second time with 10 controls (mean 51 (SD 24), median: 43 (25-84) $\mathrm{mg} / \mathrm{g}$ creatinine) and 15 laminators (mean 695 (SD 664), median: 578 (105-2,213) mg/g creatinine), who had MA and PGA concentrations below or above 100 $\mathrm{mg} / \mathrm{g}$ creatinine respectively. These calculations showed no relevant changes in the results. Also the correlation coefficients between the sum of MA and PGA and parameters of hearing ability were calculated once more including all 32 participants. These calculations showed no significant associations at all. A second limitation of the study is the fact, that previous noise exposures could not be quantified. Not documented or unknown previous noise exposures are a common difficulty in field studies addressed to the question of a possible effect of a chemical on hearing ability. Because noise and styrene exposures frequently occur simultaneously in industrial environments it might be difficult to distinguish between the influences of these two independent factors concerning their possible effects on the auditory system.

Our findings confirm the results of previous field studies on styrene exposed workers ${ }^{7,8,12)}$. Also Muijser et al. (1988) did not find any difference between 59 styrene exposed workers and 88 controls engaged in the production of photographic films in pure-tone thresholds up to $16 \mathrm{kHz}^{6}$. A statistically significant difference was only found within the styrene group between the most and the least exposed workers. This could be due to the duration of workers noise exposure, which is highly correlated to styrene exposure.

On the other hand, in two recent publications the authors concluded, that styrene exposure may increase hearing loss of the auditory system even below recommended exposure values ${ }^{10,11)}$. Morata et al. (2002) examined 313 workers, who were exposed to styrene, noise or both ${ }^{10)}$. Exposure levels were determined for styrene in air, biological monitoring and noise. Styrene exposure did not exceed the limit value of $20 \mathrm{ppm}$. The authors reported "significantly poorer pure-tone thresholds at the frequencies 2, 3, 4 and $6 \mathrm{kHz}$ for the styrene exposed workers for both ears, compared with both of the two groups not exposed to styrene". Sliwinska-Kowalska et al. (2003) studied 290 workers exposed to a mixture of organic solvents with styrene as its main compound ${ }^{11)}$. The mean hearing thresholds were significantly higher in the exposed group than in the unexposed group at all frequencies tested. The fact that no biological monitoring was used to objectify the individual body burden of the workers makes it difficult to interpret the results, because the ototoxic effect on the auditory system is carried out 
by internal exposure. Therefore the level of airborne exposure is not a sufficient indicator, because of considerable inter- and intra-individual variations in uptake and metabolism, the percutaneous absorption rate and the use of respiratory masks.

The results of this study did not support the assumption that occupational exposure to styrene in concentration of the current occupational exposures in Germany is related to a significant decrease in hearing acuity. However further studies, especially under controlled experimental settings and with a design which is suitable to separate the impact of noise and styrene are necessary to clear up the open question of a styrene induced hearing loss.

\section{References}

1) Jensen A A, Breum NO, Bacher J, Lynge E (1990) Occupational exposures to styrene in Denmark 1955-88. Am J Ind Med 17, 593-606.

2) Lemasters GK, Carson A, Samuels SJ (1985) Occupational styrene exposure for twelve product categories in the reinforced-plastics industry. Am Ind Hyg Assoc J 46, 434-41.

3) Crofton KM, Lassiter TL, Rebert CS (1994) Solventinduced ototoxicity in rats: an atypical selective midfrequency hearing deficit. Hear Res 80, 25-30.

4) Makitie A, Pirvola U, Pyykko I, Sakakibara H, Riihimaki V, Ylikoski J (2002) Functional and morphological effects of styrene on the auditory system of the rat. Arch Toxicol 76, 40-7.

5) Lataye R, Campo P, Loquet G (2000) Combined effects of noise and styrene exposure on hearing function in the rat. Hear Res 139, 86-96.

6) Muijser, H, Hoogendijk EM, Hooisma J (1988) The effects of occupational exposure to styrene on high-fre- quency hearing thresholds. Toxicology 49, 331-40.

7) Möller C, Ödkvist L, Larsby B, Tham R, Ledin T, Bergholtz L (1990) Otoneurological findings in workers exposed to styrene. Scand J Work Environ Health 16, 189-94.

8) Sass-Kortsak AM, Corey PN, Robertson JM (1995) An investigation of the association between exposure to styrene and hearing loss. Ann Epidemiol 5, 15-24.

9) Morioka I, Kuroda M, Miyashita K, Takeda S (1999) Evaluation of organic solvent ototoxicity by the upper limit of hearing. Arch Environ Health 54, 341-46.

10) Morata TC, Johnson A-C, Nylen P, Svensson EB, Cheng J, Krieg EF, Lindblad AC, Ernstgard L, Franks J (2002) Audiometric findings in workers exposed to low levels of styrene and noise. J Occup Environ Med 44, 806-14.

11) Sliwinska-Kowalska M, Zamyslowska-Szmytke E, Szymczak W, Kotylo P, Fiszer M, Wesolowski W, Pawlaczyk-Luszczynska M (2003) Ototoxic effects of occupational exposure to styrene and co-exposure to styrene and noise. J Occup Environ Med 45, 15-24.

12) Calabrese G, Martini A, Sessa G, Cellini M, Bartolucci GB, Marcuzzo G, de Rosa E (1996) Otoneurological study in workers exposed to styrene in the fiberglass industry. Int Arch Occup Environ Health 68, 219-23.

13) Deutsche Forschungsgemeinschaft (DFG) (2004) List of MAK and BAT values 2004. Commission for the investigation of health hazards of chemical compounds in the work area: Report No. 40. Wiley-VCH, city.

14) Deutsche Forschungsgemeinschaft (DFG) (1988) Analyses of hazardous substances in biological materials. Methods for biological monitoring. In: Aromatic carboxylic acids. Vol 2. eds. by Angerer J, Schaller $\mathrm{KH}$, 47-66, Wiley-VCH, Weinheim.

15) Pouyatos B, Campo P, Lataye R (2002) Use of DPOAEs for assessing hearing loss caused by styrene in the rat. Hear Res 165, 156-64. 